\title{
Resonant optical absorption and defect control in $\mathrm{Ta}_{3} \mathrm{~N}_{5}$ photoanodes
}

\author{
A. Dabirian ${ }^{\text {a) }}$ and R. van de Krol ${ }^{\text {b) }}$ \\ Materials for Energy Conversion and Storage (MECS), Department of Chemical Engineering, \\ Delft University of Technology, P.O. Box 5045, 2600GA Delft, The Netherlands
}

(Received 13 November 2012; accepted 7 January 2013; published online 23 January 2013)

\begin{abstract}
In this study, we explore resonance-enhanced optical absorption in $\mathrm{Ta}_{3} \mathrm{~N}_{5}$ photoanodes for water splitting. By using a reflecting Pt back-contact and appropriate $\mathrm{Ta}_{3} \mathrm{~N}_{5}$ film thickness, the resonance frequency can be tuned to energies just above the bandgap, where the optical absorption is normally weak. The resonance results in a significant improvement in the photoanode's incident photon-to-current efficiency. The $\mathrm{Ta}_{3} \mathrm{~N}_{5}$ films are made by high-temperature nitridation of $\mathrm{Ta}_{2} \mathrm{O}_{5}$. The nitridation time is found to be critical, as extended nitridation result in the formation of nitrogen vacancies through thermal reduction. These insights give important clues for the development of efficient (oxy)nitride-based photoelectrodes. (C) 2013 American Institute of Physics. [http://dx.doi.org/10.1063/1.4788930]
\end{abstract}

By splitting water into hydrogen and oxygen, photoelectrochemical (PEC) cells ${ }^{1-3}$ can directly convert solar energy into chemical energy. This is a clean and efficient route to store energy in the form of a solar fuel. ${ }^{4,5}$ Most PEC devices are based on an n-type semiconducting photoanode that oxidizes water. The reduction of water is carried out at a metallic or semiconducting counter-electrode. In the on-going search for suitable photoanode materials, tantalum nitride $\left(\mathrm{Ta}_{3} \mathrm{~N}_{5}\right)$ has attracted an increasing amount of attention. This is due to its nearly ideal bandgap $(2.1 \mathrm{eV})$ and its nearly ideal band-edge positions that allow the material to drive both the anodic and the cathodic water splitting reactions. ${ }^{6-18}$

$\mathrm{Ta}_{3} \mathrm{~N}_{5}$ is usually prepared by nitridation of tantalum oxide $\left(\mathrm{Ta}_{2} \mathrm{O}_{5}\right)$ in ammonia $\left(\mathrm{NH}_{3}\right)$ atmosphere at elevated temperatures. So far, Higashsi et al. ${ }^{13}$ have demonstrated the most efficient $\mathrm{Ta}_{3} \mathrm{~N}_{5}$ photoanodes prepared by electrophoretic deposition of $\mathrm{Ta}_{3} \mathrm{~N}_{5}$ nanoparticles. They used $2 \mu \mathrm{m}$ thick nanoparticulate films to ensure sufficient visible light absorption. The main challenge was to enhance the electronic contact between the particles. Even at temperatures as high as $850^{\circ} \mathrm{C}$, the $\mathrm{Ta}_{3} \mathrm{~N}_{5}$ particles do not sinter well, ${ }^{14}$ resulting in poor inter-particle electron transport and low photocurrents. To address this, a post-deposition necking treatment with $\mathrm{TaCl}_{5}$ was used. While this approach worked well, the necking treatment complicates the synthesis process and makes it challenging to reproduce.

An alternative approach that waives the need for a necking process is to use thin compact films. Similar to the powder route, these films can also be made by converting $\mathrm{Ta}_{2} \mathrm{O}_{5}$ into $\mathrm{Ta}_{3} \mathrm{~N}_{5}$ through a high-temperature treatment in $\mathrm{NH}_{3}$. Unfortunately, films thicker than a few hundred nanometers delaminate due to the accumulation of internal stress during the conversion. This present a challenge, since a few hundred nanometers is not enough to absorb all incident light, especially near the absorption edge. Therefore, a suitable light

\footnotetext{
${ }^{a)}$ Present address: Department of Physics, Sharif University of Technology, Tehran, Iran.

b) Present address: Institute for Solar Fuels, Helmholtz-Zentrum Berlin für Materialien und Energie Gmbh, Berlin, Germany. Electronic mail: roel. vandekrol@helmholtz-berlin.de.
}

management strategy is needed to enhance the optical absorption.

A second challenge that needs to be addressed is the presence of defects. The Domen group reported that under high-temperature nitridation conditions, thermally induced anion defects appear which limit the PEC performance of $\mathrm{Ta}_{3} \mathrm{~N}_{5}$ nanoparticles. ${ }^{10-12}$ While the nature of these defects is unclear, the fact that they appear at higher temperatures (i.e., under more strongly reducing conditions) suggests the presence of nitrogen vacancies.

In this work, we aim to (i) enhance the optical absorption near the absorption edge by optical resonance, and (ii) identify the nature of the defects formed during the hightemperature nitridation treatment. Addressing these two issues will bring us a step closer towards the development of efficient tantalum nitride photoanodes.

We use compact $\mathrm{Ta}_{3} \mathrm{~N}_{5}$ films with a thickness of $200 \mathrm{~nm}$ on Pt-coated silicon wafer or on fused silica substrates (ESCO S1-UV, $1 \mathrm{~mm}$ thick) for our study. A $5 \mathrm{~nm}$ titanium adhesion layer was used at the $\mathrm{Si} / \mathrm{Pt}$ and $\mathrm{Pt} / \mathrm{Ta}$ interfaces to avoid delamination. The platinum serves both as a conducting back-contact and as an optical reflector to enhance the absorption. First, a Ta film was sputtered onto the substrate in $3 \mu$ bars partial pressure of $\operatorname{Ar}(20 \mathrm{ml} / \mathrm{min}$ flow $)$ with $100 \mathrm{~W}$ DC electric power. After oxidation of Ta thin films to $\mathrm{Ta}_{2} \mathrm{O}_{5}$ at $600^{\circ} \mathrm{C}$ in air for $5 \mathrm{~h}$, the samples were transformed to $\mathrm{Ta}_{3} \mathrm{~N}_{5}$ by annealing in a tube oven under $50 \mathrm{ml} / \mathrm{min} \mathrm{NH}_{3}$ gas flow at $800^{\circ} \mathrm{C}$ for 5,10 , and $15 \mathrm{~h}$. In some cases, the $15 \mathrm{~h}$ thermal treatment resulted in partial delamination due to thermal stress at the $\mathrm{Si} / \mathrm{Pt}$ interface, but the thickness of the Pt film $(150 \mathrm{~nm})$ ensured that this had little influence on the $\mathrm{Ta}_{3} \mathrm{~N}_{5}$ film. The crystal structures were determined using a Bruker D8 Advance X-ray diffractometer (XRD) equipped with a cobalt source $(\lambda=1.7889 \AA)$ in a Bragg-Brentano configuration. For films deposited on fused silica, UV/Vis transmission measurements were performed using a PerkinElmer Lambda-900 photospectrometer.

The photoelectrochemical performances of the films were evaluated under simulated AM $1.5 \mathrm{G}$ illumination (Newport Sol3A class AAA solar simulator, type 94023 ASR3) in a conventional three-electrode cell with a fused 

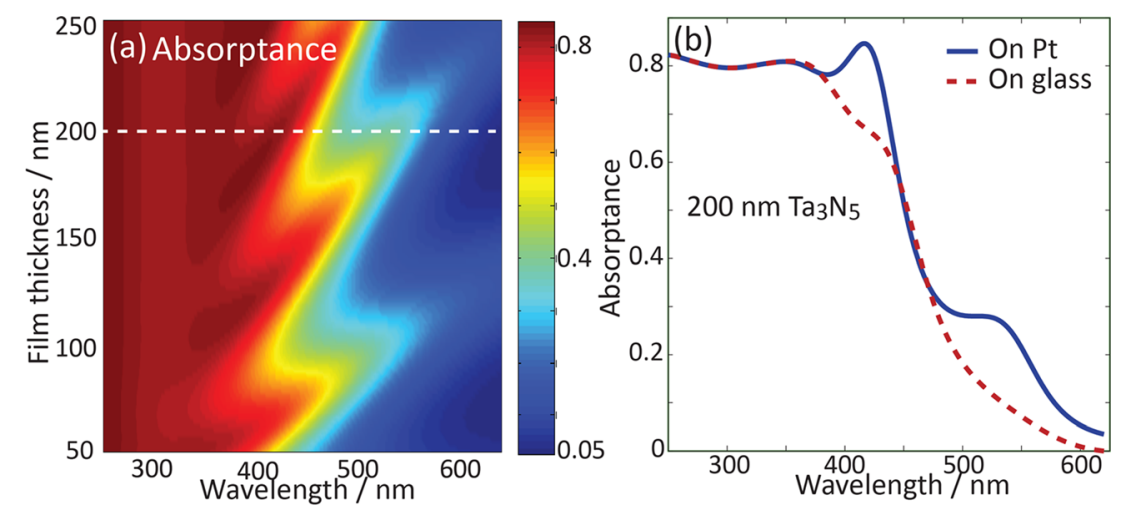

FIG. 1. (a) Calculated absorbance of a tantalum nitride thin film on platinum as a function of wavelength and film thickness and (b) the calculated optical absorptance spectra of a $200 \mathrm{~nm} \mathrm{Ta}_{3} \mathrm{~N}_{5}$ thin film on Pt and on glass. silica window, a platinum counter electrode, and an $\mathrm{Ag}$ / $\mathrm{AgCl}$ reference electrode (XR300, saturated $\mathrm{KCl} / \mathrm{AgCl}$ solution, Radiometer Analytical). An aqueous solution of $0.1 \mathrm{M}$ $\mathrm{KPi}(\mathrm{pH} \mathrm{7)}$ was used as the electrolyte. It was prepared by mixing $0.1 \mathrm{M}$ aqueous stock solutions of $\mathrm{K}_{2} \mathrm{HPO}_{4}$ and $\mathrm{KH}_{2} \mathrm{PO}_{4}$ with ratios of $61.5: 38.5$. Prior to measurement, the electrolyte was purged with Ar gas for $15 \mathrm{~min}$ to remove any dissolved oxygen. The working area of the electrodes exposed to the electrolyte was $28.3 \mathrm{~mm}^{2}$ ( $6 \mathrm{~mm}$ diameter) for all samples. A colloidal $\mathrm{IrO}_{2}$ aqueous solution was prepared using a standard recipe ${ }^{19}$ and drop-casted on the $\mathrm{Ta}_{3} \mathrm{~N}_{5}$ films as an oxygen evolution co-catalyst. Potential control was provided by a Princeton Applied Research EG\&G model 283 potentiostat. Incident photon-to-current efficiencies (IPCE) were measured in a similar setup using monochromatic light provided by a $250 \mathrm{~W}$ quartz tungsten halogen lamp coupled into an Acton SpectraPro-150i monochromator. The monochromatic light intensities were measured with a calibrated photodiode (Ophir PD300-UV). Electromagnetic simulations were performed by analytically solving Maxwell equations ${ }^{20}$ on a geometry consisting of three layers (water/Ta $\mathrm{N}_{5} / \mathrm{Pt}$ ). The refractive index for $\mathrm{Ta}_{3} \mathrm{~N}_{5}$ was acquired from Ref. 21.

All the peaks in XRD patterns of the films, synthesized at $800{ }^{\circ} \mathrm{C}$ for 5,10 , and $15 \mathrm{~h}$ under a $50 \mathrm{ml} / \mathrm{min} \mathrm{NH}_{3}$ flow, were indexed to either $\mathrm{Ta}_{3} \mathrm{~N}_{5}$ (ICDD PDF 01-079-1533) or to the Pt substrate (Fig. S1, Ref. 22). No traces of other tantalum oxide, -nitride, or -oxynitride phases were observed.

Simulation of the light absorption in $\mathrm{Ta}_{3} \mathrm{~N}_{5}$ films on $\mathrm{Pt}$, shown in Fig. 1(a) as a function of $\mathrm{Ta}_{3} \mathrm{~N}_{5}$ film thickness and wavelength, reveals the presence of pronounced peaks in the absorptance spectrum. These peaks occur due to constructive interference of the light that enters the $\mathrm{Ta}_{3} \mathrm{~N}_{5}$ film with its reflection from the $\mathrm{Pt}$ surface and with partial backreflectance from the $\mathrm{Ta}_{3} \mathrm{~N}_{5} /$ water interface. ${ }^{20} \mathrm{~A}$ similar approach has very recently been reported to enhance the optical absorption in optical coatings based on germanium ${ }^{23}$ and in ultra-thin $\mathrm{Fe}_{2} \mathrm{O}_{3}$ photoanode films. ${ }^{24}$ To maximize the photocurrent of $\mathrm{Ta}_{3} \mathrm{~N}_{5}$ films, such a resonant absorption peak should occur at wavelengths where the absorption is weakest. This situation occurs at wavelengths somewhat below the band edge, which is located at $590 \mathrm{~nm}$ for $\mathrm{Ta}_{3} \mathrm{~N}_{5}$ $\left(\mathrm{E}_{\mathrm{g}}=2.1 \mathrm{eV}\right)$. Based on these considerations, we chose a film thickness of $\sim 200 \mathrm{~nm}$ for our studies, resulting in one absorption maximum at $520 \mathrm{~nm}$ and another one at $420 \mathrm{~nm}$. Fig. 1(b) illustrates the extent to which the reflecting $\mathrm{Pt}$ back-contact enhances the optical absorption at these wave- lengths for this thickness. The structure functions as a onedimensional Gires-Tournois resonator, a variation of the well known Fabry-Perot resonator that has a highly reflecting mirror on one side (the $\mathrm{Ta}_{3} \mathrm{~N}_{5} / \mathrm{Pt}$ interface) and a partially reflecting mirror on the other side (the $\mathrm{Ta}_{3} \mathrm{~N}_{5}$-water interface). The relative absorption enhancement is smaller than that observed by Dotan et al. for their $20-40 \mathrm{~nm} \mathrm{Fe}_{2} \mathrm{O}_{3}$ photoanode films, ${ }^{24}$ which is due to the fact that we use the second-order resonance mode in our $200 \mathrm{~nm}$ film. This mode was chosen because the absolute absorptance at $520 \mathrm{~nm}$ is higher than that of the first-order mode that one would get in a $100 \mathrm{~nm}$ film, as can be seen in Fig. 1(a). The calculated absorptance, transmittance, and reflectance spectra along with field profiles inside the layer at several wavelengths are depicted in Fig. S2. ${ }^{22}$

To verify these theoretical predictions, IPCE spectra were measured for $200 \mathrm{~nm}$ thick $\mathrm{Ta}_{3} \mathrm{~N}_{5}$ films on Pt (Fig. 2). The spectra show a pronounced peak at $540 \mathrm{~nm}$, which is indeed close to the predicted resonance wavelength of $520 \mathrm{~nm}$. Smaller peaks appear in the 400-450 nm wavelength range in agreement with the calculated absorptance spectrum (Fig. 1(b)). The $20 \mathrm{~nm}$ difference between the experimental and calculated resonance wavelengths is attributed to the deviation of the film's actual refractive index from the literature value ${ }^{21}$ used for the calculation. These results confirm that resonance-enhanced absorption using a metallic backreflector can indeed enhance the photoresponse of practical photoelectrodes.

Fig. 2 further reveals that the IPCE in the visible range improves with increasing nitridation time, while the UV

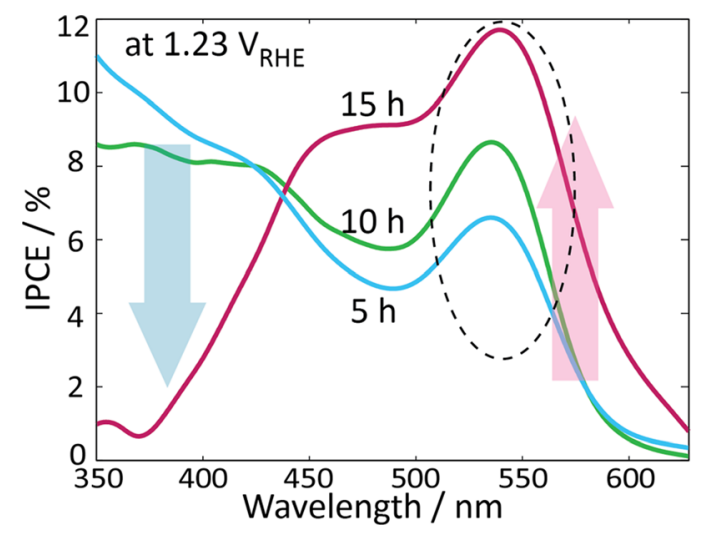

FIG. 2. Incident photon-to-current efficiencies of tantalum nitride thin films nitridized at $800^{\circ} \mathrm{C}$ for 5,10 , and $15 \mathrm{~h}$, recorded at potential $+1.23 \mathrm{~V}$ versus RHE. 


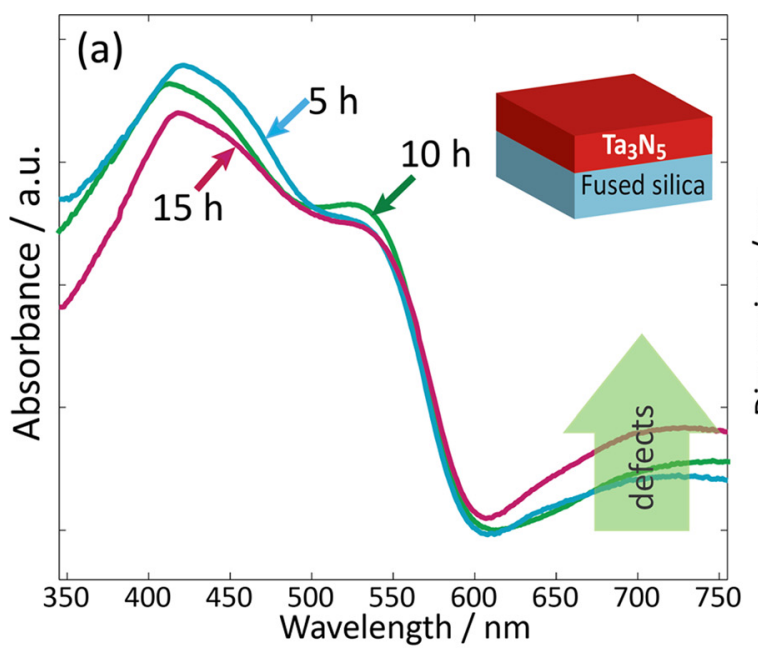

FIG. 3. Optical absorption spectra of tantalum nitride thin films on fused silica nitridized at $800^{\circ} \mathrm{C}$ for 5,10 , and $15 \mathrm{~h}$. The right-hand figure shows the calculated intensity distribution of the electric field in the structure when illuminated from the electrolyte-side with wavelengths of (b) $370 \mathrm{~nm}$ and (c) $450 \mathrm{~nm}$. response $(\lambda<440 \mathrm{~nm})$ strongly decreases. A similar trend is observed in Fig. 3(a), which shows the measured optical absorptance (1-transmittance-reflectance) of $\mathrm{Ta}_{3} \mathrm{~N}_{5}$ films deposited on fused silica. Fig $S 3^{22}$ shows the measured transmittance and reflectance spectra of the films. The enhanced subbandgap absorption around $\sim 720 \mathrm{~nm}(\sim 1.72 \mathrm{eV})$ has previously been attributed to reduced $\mathrm{Ta}^{5+},{ }^{10-12}$ presumably present at the surface of the $\mathrm{Ta}_{3} \mathrm{~N}_{5}{ }^{11}$ However, the surfaceto-bulk ratio of our $200 \mathrm{~nm}$ films $\left(0.5 \mathrm{~m}^{2} / \mathrm{g}\right)$ is much smaller than that of the powder samples studied in Refs. 11 and 12 $\left(>10 \mathrm{~m}^{2} / \mathrm{g}\right)$. The absorption is therefore more likely to be caused by a bulk defect. Since the conduction band of $\mathrm{Ta}_{3} \mathrm{~N}_{5}$ shows significant dispersion and a strong covalent interaction between $\mathrm{Ta}$ and $\mathrm{N},{ }^{25}$ an explanation in terms of trapping and de-trapping of (nearly-)free conduction band electrons at $\mathrm{Ta}^{4+} / \mathrm{Ta}^{5+}$ centers seems unlikely. Instead, we attribute the absorption band at $720 \mathrm{~nm}$ to the presence of ionic defects, presumably anion vacancies that form during prolonged nitridation. This is consistent with the increased metallic (broad-band) reflection of films nitridized for $15 \mathrm{~h}$ (Fig. $\mathrm{S} 3(\mathrm{~b})^{22}$, which is caused by free electrons that chargecompensate the positively charged anion vacancies.

The mechanism for the formation of nitrogen vacancies upon prolonged exposure to the $\mathrm{NH}_{3}$ atmosphere ${ }^{10-12}$ is not clear. It seems counter-intuitive that nitrogen would first enter the structure in order to convert $\mathrm{Ta}_{2} \mathrm{O}_{5}$ to $\mathrm{Ta}_{3} \mathrm{~N}_{5}$, and then leave the structure again after a certain amount of time. A possible clue is given by observations of Henderson and Hector, who found that a certain amount of oxygen always remains present on the 3-coordinate nitrogen sites in the $\mathrm{Ta}_{3} \mathrm{~N}_{5}$ structure. ${ }^{26}$ By combining powder neutron diffraction data with Thermal Gravimetric Analysis (TGA) and combustion microanalysis, they inferred a roughly stoichiometric composition of $\sim \mathrm{Ta}_{3} \mathrm{~N}_{4.7} \mathrm{O}_{0.3}$ after $8 \mathrm{~h}$ of annealing at $800^{\circ} \mathrm{C}$. Continued annealing up to $120 \mathrm{~h}$ increased the nitrogen content and decreased the oxygen content of their samples, as one might expect. Crucially, however, the decrease in O-content was larger than the increase in $\mathrm{N}$-content, resulting in a sub-stoichiometric phase with an approximate composition of $\sim \mathrm{Ta}_{3} \mathrm{~N}_{4.8} \mathrm{O}_{0.13}$. In addition to the singly charged oxygen ions on nitrogen lattice sites $\left(O_{N}^{*}\right)$ that were also present in $\mathrm{Ta}_{3} \mathrm{~N}_{4.7} \mathrm{O}_{0.3}$, this phase also contains triply charged vacancies on the nitrogen sublattice $\left(V_{N}^{\cdots}\right)$. The high charge of the nitrogen vacancy makes it a likely candidate as the deep donor state responsible for the absorption feature at $\sim 720 \mathrm{~nm}$.

Compared to the changes in IPCE upon prolonged nitridation (Fig. 2), the changes in the optical absorption (Fig. 3) are relatively small. Although this can be partly explained by the absence of the metallic back-reflector for the optical absorption measurements, it is likely that other factors play an even more important role. Of particular interest is the influence of defects on the charge transport properties of $\mathrm{Ta}_{3} \mathrm{~N}_{5}$. In the visible region, electron-hole pairs are generated throughout the entire film and the photoresponse is therefore sensitive to the bulk charge transport properties. With this in mind, the improvement of the photocurrent in the visible range is mainly attributed to a decrease in the number of structural defects, such as dislocations, amorphous regions, and grain boundaries. The reduction in the number of grain boundaries is indeed evidenced by an increase in crystallite size during annealing; from the broadening of the $\mathrm{Ta}_{3} \mathrm{~N}_{5}(040)$ peak $(\mathrm{d}=2.553 \AA)$, crystallite sizes of 22,32 , and $36 \mathrm{~nm}$ were calculated using Scherrer's equation for samples treated for 5,10 , and $15 \mathrm{~h}$, respectively.

In the UV range of the spectrum, the penetration depth of the incident light is much shorter. This is illustrated by Fig. 3(b), which shows the calculated intensity profile of the electric field of $370 \mathrm{~nm}$ light propagating in the $\mathrm{Ta}_{3} \mathrm{~N}_{5}$ layer. Most of this light is absorbed within the first $20 \mathrm{~nm}$ from the surface. In contrast, the $450 \mathrm{~nm}$ light propagates throughout the entire thickness of the film (Fig. 3(c)). The photoresponse in the UV region is therefore mainly determined by defects in the (sub-) surface region of the film. This is consistent with the mechanism described above, where anion vacancies are created by oxygen- and nitrogen-exchange via the gas phase.

Fig. 4 shows the I-V curves of the samples before and after $\mathrm{IrO}_{2}$ treatment under AM 1.5 illumination and in the dark. For the untreated samples, a nitridation time of $10 \mathrm{~h}$ gives the optimal performance resulting in a photocurrent density of $0.37 \mathrm{~mA} \mathrm{~cm}^{-2}$ at $1.23 \mathrm{~V}$ versus RHE (Reversible Hydrogen Energy scale). This sample has the optimal balance of a small number of surface defects (short nitridation time to prevent reduction of $\mathrm{Ta}_{3} \mathrm{~N}_{5-\mathrm{x}} \mathrm{O}_{\mathrm{x}}$ to $\mathrm{Ta}_{3} \mathrm{~N}_{5-\mathrm{x}} \mathrm{O}_{\mathrm{x}-\delta}$ ) and few grain boundaries that hinder charge transport (long 


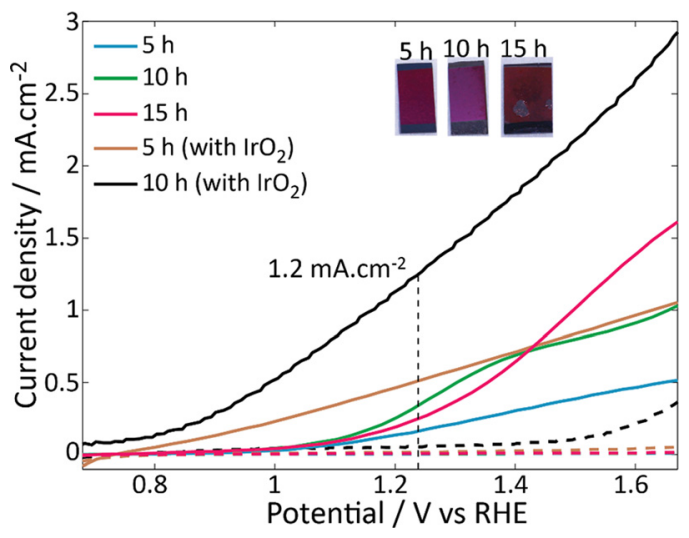

FIG. 4. Current vs. voltage curves of photoanodes nitridized at $800^{\circ} \mathrm{C}$ for 5,10 , and $15 \mathrm{~h}$ in the dark (dashed lines) and under simulated AM 1.5 illumination (solid lines). The inset shows a photograph of the samples.

enough nitridation for crystallization and crystal growth). The performance of these untreated samples is limited by slow water oxidation kinetics, i.e., slow charge transfer across the semiconductor/electrolyte interface. To improve the kinetics, we treated the 5 and $10 \mathrm{~h}$ samples with an aqueous solution of colloidal $\mathrm{IrO}_{2}$ nanoparticles as a water oxidation catalyst. ${ }^{19,27}$ After $\mathrm{IrO}_{2}$ treatment, these samples show a 4-fold improvement in their photoresponse, reaching photocurrent densities of 0.42 and $1.2 \mathrm{~mA} \mathrm{~cm}^{-2}$, respectively. While part of this photocurrent might be due to photocorrosion of $\mathrm{Ta}_{3} \mathrm{~N}_{5}$, the increase in photocurrent after applying the $\mathrm{IrO}_{2}$ catalyst can be fully attributed to water oxidation. This means that the photocurrent due to water oxidation is at least $1.2-0.37=0.8 \mathrm{~mA} / \mathrm{cm}^{2}$. These results demonstrate that the $\mathrm{IrO}_{2}$ treatment solves the issue with interfacial charge transfer. However, bulk charge transport and limited visible light absorption remain factors that limit the PEC performance of $\mathrm{Ta}_{3} \mathrm{~N}_{5}$ thin films. These limiting factors need to be overcome by using, e.g., guest-host nanostructuring approaches ${ }^{28}$ and/ or near-field absorption enhancement based on surface plasmon resonances. ${ }^{29}$

In summary, our study of $\mathrm{Ta}_{3} \mathrm{~N}_{5}$ photoanodes shows that the presence of a metallic back-contact can greatly enhance the photocurrent quantum efficiency through resonant optical absorption. An important advantage of this method over near-field approaches based on localized surface plasmons is the absence of noble metal particles embedded in or adsorbed at the surface of the absorber film. These metal particles often introduce efficient recombination pathways that, despite the enhanced optical absorption, decrease the overall photoelectrochemical performance of the photoelectrode. ${ }^{30}$ In addition, we showed that the duration of the hightemperature nitridation treatment for the conversion of $\mathrm{Ta}_{2} \mathrm{O}_{5}$ to $\mathrm{Ta}_{3} \mathrm{~N}_{5}$ is critical. The treatment needs to be sufficiently long to obtain crystalline samples with as few as possible grain boundaries, while it needs to be kept short enough to avoid the formation of deep traps in the form of nitrogen vacancies through thermal reduction. Combining these insights may lead to alternative design strategies for efficient (oxy)nitride-based photoelectrodes.

We gratefully acknowledge the European Commission's Framework Project 7 (NanoPEC, Project 227179) for financial support of this work.

\section{${ }^{1}$ M. Grätzel, Nature 414, 338 (2001).}

${ }^{2}$ R. van de Krol and M. Grätzel, Photoelectrochemical Hydrogen Production (Springer, New York, 2012).

${ }^{3}$ R. van de Krol, Z. Liang, and J. Schoonman, J. Mater. Chem. 18, 2311 (2008).

${ }^{4}$ G. A. Olah, Angew. Chem., Int. Ed. 44, 2636 (2005).

${ }^{5}$ G. W. Crabtree, M. S. Dresselhaus, and M. V. Buchanan, Phys. Today 57, 39 (2004).

${ }^{6}$ K. Maeda and K. Domen, J. Phys. Chem. Lett. 1, 2655 (2010).

${ }^{7}$ G. Hitoki, A. Ishikawa, T. Takata, J. N. Kondo, M. Hara, and K. Domen, Chem. Lett. 7, 736 (2002).

${ }^{8}$ W.-J. Chun, A. Ishikawa, H. Fujisawa, T. Takata, J. N. Kondo, M. Hara, M. Kawai, Y. Matsumoto, and K. Domen, J. Phys. Chem. B 107, 1798 (2003).

${ }^{9}$ M. Hara, G. Hitoki, T. Takata, J. N. Kondo, H. Kobayashi, and K. Domen, Catal. Today 78, 555 (2003).

${ }^{10}$ Y. Lee, K. Nukumizu, T. Watanabe, T. Takata, M. Hara, M. Yoshimura, and K. Domen, Chem. Lett. 35, 352 (2006).

${ }^{11}$ K. Maeda, N. Nishimura, and K. Domen, Appl. Catal. A 370, 88 (2009).

${ }^{12}$ L. Yuliati, J.-H. Yang, X. Wang, K. Maeda, T. Takata, M. Antonietti, and K. Domen, J. Mater. Chem. 20, 4295 (2010).

${ }^{13}$ M. Higashi, K. Domen, and R. Abe, Energy Environ. Sci. 4, 4138 (2011).

${ }^{14}$ M. Tabata, K. Maeda, M. Higashi, D. Lu, T. Takata, R. Abe, and K. Domen, Langmuir 26, 9161 (2010).

${ }^{15}$ D. Yokoyama, H. Hashiguchi, K. Maeda, T. Minegishi, T. Takata, R. Abe, J. Kubota, and K. Domen, Thin Solid Films 519, 2087 (2011).

${ }^{16}$ X. Feng, T. J. La Tempa, J. I. Basham, G. K. Mor, O. K. Varghese, and C. A. Grimes, Nano Lett. 10, 948 (2010).

${ }^{17}$ Y. Cong, H. S. Park, H. X. Dang, F.-R. F. Fan, A. J. Bard, and C. Buddie Mullins, Chem. Mater. 24, 579 (2012).

${ }^{18}$ Y. Cong, H. S. Park, S. Wang, H. X. Dang, F.-R. F. Fan, C. Buddie Mullins, and A. J. Bard, J. Phys. Chem. C 116, 14541 (2012).

${ }^{19}$ S. D. Tilley, M. Cornuz, K. Sivula, and M. Grätzel, Angew. Chem., Int. Ed. 49, 6405 (2010).

${ }^{20}$ W. C. Chew, Waves and Fields in Inhomogeneous Media (Wiley-IEEE, New York, 1999).

${ }^{21}$ E. Langereis, S. B. S. Heil, H. C. M. Knoops, W. Keuning, M. C. M. van de Sanden, and W. M. M. Kessels, J. Phys. D: Appl. Phys. 42, 073001 (2009).

${ }^{22}$ See supplementary material at http://dx.doi.org/10.1063/1.4788930 for Figs. S1, S2, and S3.

${ }^{23}$ M. A. Kats, R. Blanchard, P. Genevet, and F. Capasso, "Nanometre optical coatings based on strong interference effects in highly absorbing media" Nature Mater. 12, 20-24 (2013).

${ }^{24}$ H. Dotan, O. Kfir, E. Sharlin, O. Blank, M. Gross, I. Dumchin, G. Ankonina, and A. Rothschild, "Resonant light trapping in ultrathin films for water splitting" Nature Mater. (published online).

${ }^{25}$ C. M. Fang, E. Orhan, G. A. de Wijs, H. T. Hintzen, R. A. de Groot, R. Marchand, J.-Y. Saillard, and G. de With, J. Mater. Chem. 11, 1248 (2001).

${ }^{26}$ S. J. Henderson and A. L. Hector, J. Solid State Chem. 179, 3518 (2006).

${ }^{27}$ R. Abe, M. Higashi, and K. Domen, J. Am. Chem. Soc. 132, 11828 (2010).

${ }^{28}$ Y. Lin, S. Zhou, S. W. Sheehan, and D. Wang, J. Am. Chem. Soc. 133, 2398 (2011)

${ }^{29}$ I. Thomann, B. A. Pinaud, Z. Chen, B. M. Clemens, T. F. Jaramillo, and M. L. Brongersma, Nano Lett. 11, 3440 (2011).

${ }^{30}$ E. Thimsen, F. Le Formal, M. Grätzel, and S. C. Warren, Nano Lett. 11, 35 (2011). 